\title{
Awareness about the necessity of vestibular rehabilitation education in Korean physical therapists
}

\author{
Yun-Hee Sung* \\ Department of Physical Therapy, College of Health Sciences, Kyungnam University, Changwon, Korea
}

Vestibular rehabilitation (VR) improves dizziness and vertigo, postural control, and quality of life. It is a beneficial and safe intervention for patients with peripheral vestibular disease. Physical therapists play an important role in treating them, but Korean physical therapists have little experience in VR or treating peripheral vestibular disease. Furthermore, there are few studies on the current status of Korean physical therapists regarding VR. Therefore, we aimed to identify the awareness and current status of Korean physical therapists regarding VR and to discuss the necessity of VR education. The data were obtained from an online survey conducted among 483 licensed physical therapists. In total, 393 questionnaires were analyzed, after excluding 90 questionnaires $(18.6 \%)$ with poor answers. Most physical therapists had no VR education $(75.6 \%)$ and had a high positive response for the necessity of VR education (68.2\%) and intention to receive VR education (63.9\%). There was a significant difference in clinical experience and intention to receive VR education $(P<0.05)$ with respect to presence or absence of VR education. For the necessity of VR education, there was a statistically significant difference in academic background, institutional type, and intention to receive VR education $(P<0.05)$. In conclusion, many physical therapists in Korea are very interested in VR education, and various factors have highlighted the need for VR education. Therefore, professional education for VR and the cooperation and attention of related medical staff are urgently required.

Keywords: Vestibular rehabilitation, Education, Physical therapist

\section{INTRODUCTION}

Dizziness and vertigo are common and challenging complaints in a hospital. About 20\%-30\% of the world's population has experienced dizziness and vertigo; in Korea, the prevalence rate is reported to be $16.70 \%$ in adults aged 40 and older (Koo et al., 2015; van Vugt et al., 2017; von Brevern and Neuhauser, 2011). The most common cause of dizziness and vertigo is peripheral vestibular disease including peripheral vestibular hypofunction, Meniere disease, and benign paroxysmal positional vertigo (van Vugt et al., 2017). To treat these diseases, various treatments such as vestibular rehabilitation (VR), medication, and canalith repositioning technique are applied. Of these, VR and medication are prescribed for patients with peripheral vestibular hypofunction (Fishman et al., 2011; Goudakos et al., 2014). Medication has limited effectiveness, and repeated treatment with the drug is known to inter- fere with vestibular function recovery. VR has been reported to have a positive effect (Kim, 2007; McDonnell and Hillier, 2015).

In the 1940s, otolaryngologist Cawthorne and physiotherapist Cooksey developed an exercise-based intervention to rehabilitate soldiers with brain damage and dizziness (Cawthorne, 1944; Cooksey, 1946). Since the 1970s, studies on physiology, pathology, functional tests, and compensatory mechanism of the vestibular system have been actively conducted, and rehabilitation therapy for patients with vestibular disorders has been administered since the 1980s (Courjon et al., 1977; Fetter and Zee, 1988; Igarashi et al., 1981; Lacour et al., 1985; Rhee et al., 2006). VR consists of eye, head, and body movements to promote recovery and compensation (van Vugt et al., 2017; Whitney et al., 2016). The goal of these exercises is to reduce dizziness and imbalance and improve quality of life (McDonnell and Hillier, 2015).

In Korea, VR was introduced in the 1990s; however, its imple-
${ }^{*}$ Corresponding author: Yun-Hee Sung (D) https://orcid.org/0000-0002-4877-9784 Department of Physical Therapy, College of Health Sciences, Kyungnam University, 7 Kyungnamdaehak-ro, Masanhappo-gu, Changwon 51767, Korea

E-mail: sungpt97@kyungnam.ac.kr

Received: February 26, 2020 / Accepted: March 24, 2020
This is an Open Access article distributed under the terms of the Creative Commons Attribution Non-Commercial License (https://creativecommons.org/licenses/by-nc/4.0/) which permits unrestricted non-commercial use, distribution, and reproduction in any medium, provided the original work is properly cited. 
mentation is infrequent because of the lack of understanding and cooperation among clinicians in rehabilitation medicine, psychiatry, and psychology (Rhee et al., 2006). Physical therapists also face difficulties in treating patients who have dizziness and vertigo because they are unaware of VR. Therefore, we aimed to identify the awareness and current status of Korean physical therapists regarding VR and to discuss the necessity of VR education.

\section{MATERIALS AND METHODS}

\section{Participants and survey}

This study conducted an online survey for 5 days from May 27 to May 31, 2019. Of the total of 483 questionnaires, 393 were analyzed, after excluding 90 (18.6\%) with poor answers. Data collection was performed after explaining the purpose of this study and obtaining informed consent from the participants. The questionnaire consisted of six questions on general characteristics, five questions in the field of physical therapy and education, and six questions about VR education.

\section{Data analysis}

The results are expressed as frequency and percentage. The collected data were verified at the significance level of 0.05 using IBM SPSS Statistics ver. 21 (IBM SPSS Inc., Armonk, NY, USA). The chi-square test was conducted to investigate the relationship between sex, academic background, institutional type, clinical experience according to the presence or absence of VR education, and necessity of VR education. The reliability of the questionnaire was high (Cronbach alpha $=0.77$ ) in the category related to VR education.

\section{RESULTS}

Table 1 showed general characteristics of respondents. There was no statistically significant difference in the sex, academic background, institutional type, and necessity of VR education according to the presence or absence of VR education $(P>0.05)$. However, there was a statistically significant difference in clinical experience and intention to receive VR education according to the presence or absence of VR education $(P<0.05)$. Among those who had VR education, most worked in the field of neurological physical therapy, and those who did not mainly worked in the field of orthopedic physical therapy. Those who had VR education participated mainly in workshops (50\%). Regarding the reasons for attending VR education, most of those who did or did not have VR educa-
Table 1. General characteristics

\begin{tabular}{|c|c|}
\hline Characteristic & No. $(\%)$ \\
\hline \multicolumn{2}{|l|}{ Sex } \\
\hline Female & $179(45.5)$ \\
\hline Male & $214(54.5)$ \\
\hline Total & $393(100)$ \\
\hline \multicolumn{2}{|l|}{ Age (yr) } \\
\hline $20-29$ & 156 (39.7) \\
\hline 30-39 & $143(36.4)$ \\
\hline $40-49$ & $77(19.6)$ \\
\hline $50-59$ & $17(4.3)$ \\
\hline$\geq 60$ & $0(0)$ \\
\hline Total & $393(100)$ \\
\hline \multicolumn{2}{|c|}{ Academic background } \\
\hline Associate degree & $101(25.7)$ \\
\hline Bachelor's degree & $189(48.1)$ \\
\hline Master's degree & $72(18.3)$ \\
\hline Doctoral degree & $31(7.9)$ \\
\hline Total & $393(100)$ \\
\hline \multicolumn{2}{|l|}{ Places of work } \\
\hline Capital area & $86(21.9)$ \\
\hline Chungcheong-do & $80(20.4)$ \\
\hline Gangwon-do & $3(0.7)$ \\
\hline Gyeongsang-do & $215(54.7)$ \\
\hline Jeolla-do & $9(2.3)$ \\
\hline Jeju-do & $0(0)$ \\
\hline Total & $393(100)$ \\
\hline \multicolumn{2}{|l|}{ Institutional type } \\
\hline Hospital & $234(59.5)$ \\
\hline Clinic & $71(18.1)$ \\
\hline Others & $88(22.4)$ \\
\hline Total & $393(100)$ \\
\hline \multicolumn{2}{|c|}{ Clinical experience (yr) } \\
\hline $1-4$ & $169(43.0)$ \\
\hline $5-9$ & $98(24.9)$ \\
\hline$\geq 10$ & $126(32.1)$ \\
\hline Total & $393(100)$ \\
\hline \multicolumn{2}{|c|}{ Clinical field (multiple choices) } \\
\hline Neurology & 202 (36.6) \\
\hline Orthopedics & $212(38.4)$ \\
\hline Pediatrics & $41(7.4)$ \\
\hline Geriatrics & $47(8.5)$ \\
\hline Cardiopulmonary & $21(3.8)$ \\
\hline Others & $29(5.3)$ \\
\hline Total & $552(100)$ \\
\hline \multicolumn{2}{|c|}{ Necessity of clinical education } \\
\hline Yes & 365 (92.9) \\
\hline No & $28(7.1)$ \\
\hline Total & $393(100)$ \\
\hline
\end{tabular}

(Continued to the next page) 
Table 1. Continued

\begin{tabular}{|c|c|c|c|}
\hline Characteristic & №. $(\%)$ & Characteristic & №. $(\%)$ \\
\hline Received clinical education & & Others & $20(20.8)$ \\
\hline Yes & $315(80.2)$ & Total & $96(100)$ \\
\hline No & $78(19.8)$ & \multicolumn{2}{|l|}{ Necessity of VR education } \\
\hline Total & $393(100)$ & Very low & $9(2.3)$ \\
\hline \multicolumn{2}{|c|}{ Satisfaction of clinical education (people who received clinical education) } & Low & $9(2.3)$ \\
\hline Very low & $5(1.6)$ & A little low & $27(6.9)$ \\
\hline Low & $8(2.5)$ & Common & $80(20.3)$ \\
\hline A little low & $11(3.5)$ & A little high & $131(33.3)$ \\
\hline Common & $72(22.9)$ & High & $51(13.0)$ \\
\hline A little high & $124(39.4)$ & Very high & $86(21.9)$ \\
\hline High & $60(19.0)$ & Total & $393(100)$ \\
\hline Very high & $35(11.1)$ & \multicolumn{2}{|l|}{ Intention to receive VR education } \\
\hline Total & $315(100)$ & Very low & $12(3.0)$ \\
\hline \multicolumn{2}{|c|}{ Clinical application after clinical education (people who received clinical education) } & Low & $14(3.6)$ \\
\hline $\begin{array}{l}\text { Very low } \\
\text { Low }\end{array}$ & $\begin{array}{r}2(0.6) \\
10(32)\end{array}$ & A little low & $37(9.4)$ \\
\hline A little low & $24(7.6)$ & Common & $79(20.1)$ \\
\hline Common & $88(27.9)$ & A little high & $108(27.5)$ \\
\hline A little high & $91(28.9)$ & High & $70(17.8)$ \\
\hline High & $67(21.3)$ & Very high & $73(18.6)$ \\
\hline Very high & $33(10.5)$ & Total & $393(100)$ \\
\hline Total & $315(100)$ & \multicolumn{2}{|l|}{ Reasons to receive VR education (multiple choices) } \\
\hline Received VR education & & To assess and treat patients with pure vestibular disorder & $316(26.8)$ \\
\hline Yes & $96(24.4)$ & To improve the balance ability of patients with neurological injury & $258(21.8)$ \\
\hline No & $297(75.6)$ & To prevent falls in the elderly & $166(14.1)$ \\
\hline Total & $393(100)$ & To determine the cause of dizziness in patients with nervous or & $255(21.6)$ \\
\hline \multicolumn{2}{|c|}{ Type of VR education (people who received VR education) } & musculoskeletal system injury & \\
\hline Workshops & $48(50)$ & To include vestibular rehabilitation in the curriculum & $139(11.8)$ \\
\hline Books & $11(11.5)$ & To move to a specialized hospital & $35(3.0)$ \\
\hline Media (including social networking platforms) & $1(1)$ & Others & $12(1.0)$ \\
\hline Formal university curriculum & $16(16.7)$ & Total & $1,181(100)$ \\
\hline
\end{tabular}

VR, vestibular rehabilitation.

tion answered that they would attend "to assess and treat patients with pure vestibular disorder," "to improve the balance ability of patients with neurological injury," and "to determine the cause of dizziness in patients with nervous or musculoskeletal system injury" (Table 2).

There was no statistically significant difference in the sex and clinical experience according to the necessity of VR education $(P>$ $0.05)$. However, there was a statistically significant difference in academic background, institutional type, and intention to receive VR education according to the necessity of VR education $(P<0.05)$. The reasons for "VR education is necessary" included: "Many patients complain of dizziness, but I do not know how to treat," "Incidence of falling increases as the elderly population increases," "I want to provide various interventions for patients with poor balance and walking ability," and "I want to learn because I do not know what VR is." The respondents believed that VR education was needed to enhance the diversity, access, and expertise of the physical therapy field. Furthermore, they answered that the necessity of VR education was more than "a little high" in all clinical fields (Table 3).

\section{DISCUSSION}

The present study suggests the urgent need of professional education for VR and the cooperation and attention of related medical staff in Korea. Most respondents with a clinical experience of $>10$ years answered that they had received VR education, whereas most of those with $<5$ years of clinical experience responded that they 
Table 2. Differences based on the received vestibular rehabilitation (VR) education

\begin{tabular}{|c|c|c|c|c|c|c|c|c|c|c|c|}
\hline \multirow{2}{*}{ Variable } & \multicolumn{3}{|c|}{ Received VR education } & \multirow{2}{*}{$\chi^{2}$} & \multirow{2}{*}{$P$-value } & \multirow{2}{*}{ Variable } & \multicolumn{3}{|c|}{ Received VR education } & \multirow{2}{*}{$\chi^{2}$} & \multirow{2}{*}{$P$-value } \\
\hline & Yes & No & Total & & & & Yes & No & Total & & \\
\hline Gender & & & & 1.016 & 0.314 & Necessity of VR education & & & & 10.581 & 0.102 \\
\hline Female & $48(50.0)$ & $131(44.1)$ & $179(45.5)$ & & & Very low & $2(2.1)$ & $7(2.4)$ & $9(2.3)$ & & \\
\hline Male & $48(50.0)$ & $166(55.9)$ & $214(54.5)$ & & & Low & $2(2.1)$ & $7(2.4)$ & $9(2.3)$ & & \\
\hline Total & $96(100)$ & $297(100)$ & $393(100)$ & & & A little low & $6(6.2)$ & $21(7.0)$ & $27(6.9)$ & & \\
\hline Academic background & & & & 7.512 & 0.057 & Common & $11(11.5)$ & $69(23.2)$ & $80(20.3)$ & & \\
\hline Associate degree & $21(21.9)$ & $80(26.9)$ & $101(25.7)$ & & & A little high & $30(31.2)$ & $101(34.0)$ & $131(33.3)$ & & \\
\hline Bachelor's degree & $41(42.7)$ & $148(49.8)$ & $189(48.1)$ & & & High & $16(16.7)$ & $35(11.8)$ & $51(13.0)$ & & \\
\hline Master's degree & $21(21.9)$ & $51(17.2)$ & $72(18.3)$ & & & Very high & $29(30.2)$ & $57(19.2)$ & $86(21.9)$ & & \\
\hline Doctoral degree & $13(13.5)$ & $18(6.1)$ & $31(7.9)$ & & & Total & $96(100)$ & $297(100)$ & $393(100)$ & & \\
\hline Total & $96(100)$ & $297(100)$ & $393(100)$ & & & \multicolumn{2}{|l|}{ Intention to receive VR education } & & & 17.442 & 0.008 \\
\hline Institution type & & & & 2.659 & 0.265 & Very low & $2(2.1)$ & $10(3.4)$ & $12(3.0)$ & & \\
\hline Hospital & $61(63.5)$ & $173(58.2)$ & $234(59.5)$ & & & Low & $4(4.2)$ & $10(3.4)$ & $14(3.6)$ & & \\
\hline Clinic & $12(12.5)$ & $59(19.9)$ & $71(18.1)$ & & & A little low & $6(6.2)$ & $31(10.4)$ & $37(9.4)$ & & \\
\hline Others & $23(24.0)$ & $65(21.9)$ & $88(22.4)$ & & & Common & $16(16.7)$ & $63(21.2)$ & $79(20.1)$ & & \\
\hline Total & $96(100)$ & $297(100)$ & $393(100)$ & & & A little high & $17(17.7)$ & 91 (30.6) & $108(27.5)$ & & \\
\hline Clinical experience (yr) & & & & 6.418 & 0.040 & High & $27(28.1)$ & $43(14.5)$ & $70(17.8)$ & & \\
\hline $1-4$ & 32 (33.3) & $137(46.1)$ & $169(43.0)$ & & & Very high & $24(25.0)$ & $49(16.5)$ & $73(18.6)$ & & \\
\hline $5-9$ & $24(25.0)$ & $71(24.9)$ & $98(24.9)$ & & & Total & $96(100)$ & $297(100)$ & $393(100)$ & & \\
\hline$\geq 10$ & $40(41.7)$ & $86(29.0)$ & $126(32.1)$ & & & \multicolumn{4}{|c|}{ Reasons to receive VR education (multiple choice) } & & \\
\hline Total & $96(100)$ & $297(100)$ & $393(100)$ & & & To Assess and treat patients & $64(25.2)$ & $202(27.2)$ & $266(26.7)$ & & \\
\hline \multicolumn{4}{|l|}{ Clinical field (multiple choice) } & & & with pure vestibular disorder & & & & & \\
\hline Neurology & $61(42.7)$ & $141(34.5)$ & $202(36.6)$ & & & \multirow{3}{*}{$\begin{array}{l}\text { To Improve Balance ability for } \\
\text { patients with neurological } \\
\text { injuries }\end{array}$} & \multirow{4}{*}{$\begin{array}{l}62(24.4) \\
37(14.6)\end{array}$} & \multirow[t]{3}{*}{$162(21.8)$} & \multirow[t]{3}{*}{224 (22.5) } & & \\
\hline Orthopaedics & $41(28.7)$ & $171(41.8)$ & $212(38.4)$ & & & & & & & & \\
\hline Pediatrics & $14(9.8)$ & $27(6.6)$ & $41(7.4)$ & & & & & & & & \\
\hline Geriatrics & $14(9.8)$ & $33(8.1)$ & $47(8.5)$ & & & To prevent falls of the elderly & & $96(12.9)$ & $133(13.3)$ & & \\
\hline Cardiopulmonary & $7(4.9)$ & $14(3.4)$ & $21(3.8)$ & & & \multirow{3}{*}{$\begin{array}{l}\text { To determine the cause of } \\
\text { dizziness in patients with } \\
\text { nervous or musculoskeletal } \\
\text { system injuries }\end{array}$} & \multirow[t]{3}{*}{$60(23.6)$} & \multirow[t]{3}{*}{162 (21.8) } & \multirow[t]{3}{*}{$222(22.3)$} & & \\
\hline Others & $6(4.1)$ & $23(5.6)$ & $29(5.3)$ & & & & & & & & \\
\hline Total & 143 (24.4) & $409(100)$ & $552(100)$ & & & & & & & & \\
\hline Type of VR education & & & & & & To include vestibular & $25(9.8)$ & $90(12.1)$ & $115(11.5)$ & & \\
\hline Workshops & $48(50)$ & - & $48(50)$ & & & rehabilitation in the & & & & & \\
\hline Books & $11(11.5)$ & - & $11(11.5)$ & & & curriculum & & & & & \\
\hline Media & $1(1)$ & - & $1(1)$ & & & \multirow{2}{*}{$\begin{array}{l}\text { To move to a specialized } \\
\text { hospital }\end{array}$} & \multirow[t]{2}{*}{$5(2.0)$} & \multirow[t]{2}{*}{$24(3.2)$} & \multirow[t]{2}{*}{$29(2.9)$} & & \\
\hline University formal curriculum & $16(16.7)$ & - & $16(16.7)$ & & & & & & & & \\
\hline Others & $20(20.8)$ & - & $20(20.8)$ & & & Others & $1(0.4)$ & $7(1.0)$ & $8(0.8)$ & & \\
\hline Total & $96(100)$ & - & $96(100)$ & & & Total & $254(100)$ & $743(100)$ & $997(100)$ & & \\
\hline
\end{tabular}

Values are presented as number (\%).

${ }^{*} P<0.05$.

did not. Physical therapists treat many patients with various diseases as their clinical experience increases. It is speculated that experiences that did not solve the problems of patients with dizziness led to need for VR education. Thus, these circumstances may have played a role in understanding the importance of VR education. However, regardless of their clinical experience, most respondents answered they had no VR education. Most physical therapists who responded to this survey treated patients with neurological or mus- culoskeletal injuries, possibly because many physical therapists focus mainly on the curriculum to understand the diseases and learn to treat them. Furthermore, physical therapists are enhancing their capabilities through professional education (neurological or orthopedic physiotherapy courses, about $120-350 \mathrm{hr}$ ) to become experts in their fields after graduation (Korea Proprioceptive Neuromuscular Facilitation Association, 2020; Korean Academy of Orthopedic Manual Physical Therapy, 2020; Korean Bobath Association, 
Table 3. Differences based on the necessity of vestibular rehabilitation (VR) education

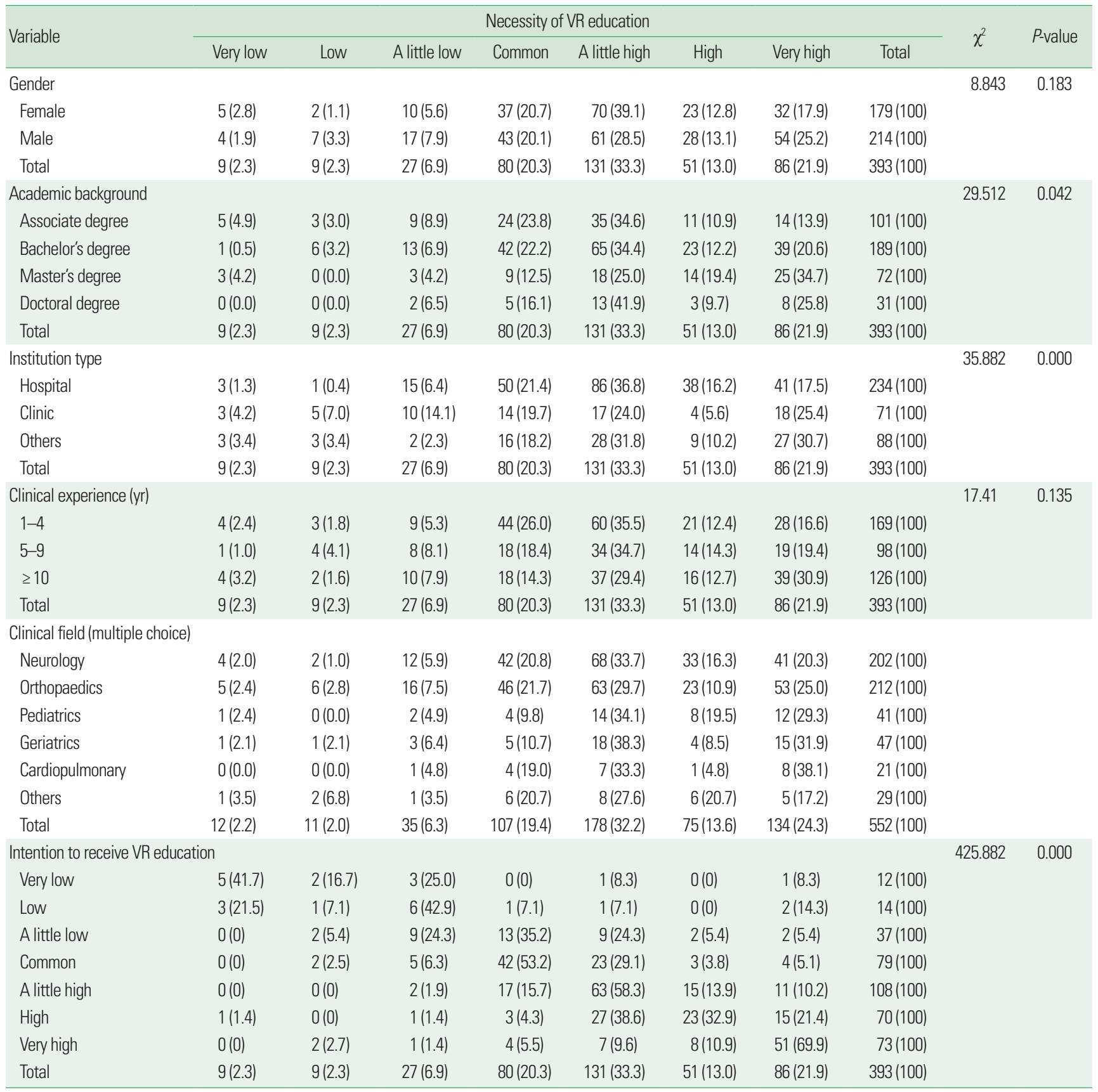

Values are presented as number $(\%)$.

${ }^{*} P<0.05$.

2020). Our study also found that $80.2 \%$ of the respondents had professional education, which is believed to develop professional ability by changing medical environment and increasing awareness of people's right to knowledge. Thus, Korean physical therapists who are less likely to treat patients with vestibular disease may have been relatively less interested in VR education.
According to a recent Cochrane review, there is moderate-to-strong evidence that VR is a safe and effective treatment for peripheral vestibular disease (McDonnell and Hillier, 2015). In many countries, VR is carried out by otolaryngologists, neurologists, rehabilitation physicians, and physical therapists. The American Physical Therapists Association has published clinical guidelines for VR 
for peripheral vestibular diseases (Hall et al., 2016). However, in Korea, VR is executed by doctors, nurses, and audiologists. After that, handouts are provided for patients to exercise at home (Kim, 2013; Lee et al., 2011). Recently, Lee and Choi-Kwon (2016) reported that the implementation rate of self-home exercise for patients with peripheral vestibular disease was very low. Many researchers reported that individualized VR tailored by a physical therapist was more effective than general VR (Gottshall, 2011; Norré and Beckers, 1988; Sessoms et al., 2015) because physical therapists play an important role in directly restoring patient function and return to daily life by identifying the patient's specific impairments and functional limitations. In addition, because physical therapists have been in continuous face-to-face contact with patients for a long time, they have a significant impact on patients' functional recovery as well as emotional well-being (Cho, 2008; Eleftheriadou et al., 2012; Shim et al., 2008; Shin and Cho, 2019). Nevertheless, physical therapists in Korea are not participating in VR because of the following reasons: insufficient cooperation among clinicians in rehabilitation medicine, otolaryngology, and neurology and absence of insurance-related items (Kim, 2013; Rhee et al., 2006). It is speculated that these factors have led to the lack of understanding of VR among physical therapists in Korea. It has led to the need for VR education. In the present study, respondents recognized a high positive response for the necessity of VR education without received VR education. However, currently, VR is not introduced in the clinical sections provided by the Korean Physical Therapy Association (2020).

Recently, the customized vestibular exercise, proposed by otolaryngologists, has been recognized as a new medical therapy (National Evidence-based Healthcare Collaborating Agency, 2020). VR is introduced through conservative education conducted by the Korea Physical Therapy Association and workshops by a special academy. Therefore, many physical therapists have stated showing interest in VR. In the present study, most of the respondents answered positively to the question "Would you attend if VR education is held?" Those who answered positively to the necessity of VR education also showed a positive intention to receive VR education. The main reasons for attending VR education were "to assess and treat patients with pure vestibular disorder," "to determine the cause of dizziness in patients with nervous and musculoskeletal system injury," and "to improve the balance ability of patients with neurological injury."

In conclusion, many Korean physical therapists recognize the necessity of VR education. However, there are few experts or organizations that can provide related education. Therefore, related as- sociations, academic societies, and expert groups should develop appropriate education and qualification programs to comply with the needs of VR education in Korea. Certain standards should be established for the organizers and the completion of education. Moreover, because Korean physical therapists do not currently have independent rights to treat rehabilitation patients by medical law, related medical staff will need to cooperate with them and recognize the importance of VR.

Lastly, this study had some limitations. First, it is difficult to generalize the study results due to the small sample size. Second, more information could not be obtained due to fewer questionnaires. Third, studies have no reported on the current status of physical therapists regarding VR in Korea. Therefore, it was difficult to compare the results of this study with those of previous studies. Nonetheless, this study may help to recognize the role and importance of VR to physical therapists in Korea.

\section{CONFLICT OF INTEREST}

No potential conflict of interest relevant to this article was reported.

\section{REFERENCES}

Cawthorne T. The physiological basis for head exercises. J Chart Soc Physiother 1944;30:106-107.

Cho MS. A study on perception of organizational culture types and job satisfaction of physical therapists. J Spec Educ Rehab Sci 2008;47:75-94.

Cooksey FS. Rehabilitation in vestibular injuries. Proc R Soc Med 1946;39: 273-278.

Courjon JH, Jeannerod M, Ossuzio I, Schmid R. The role of vision in compensation of vestibulo ocular reflex after hemilabyrinthectomy in the cat. Exp Brain Res 1977;28:235-248.

Eleftheriadou A, Skalidi N, Velegrakis GA. Vestibular rehabilitation strategies and factors that affect the outcome. Eur Arch Otorhinolaryngol 2012;269:2309-2316.

Fetter M, Zee DS. Recovery from unilateral labyrinthectomy in rhesus monkey. J Neurophysiol 1988;59:370-393.

Fishman JM, Burgess C, Waddell A. Corticosteroids for the treatment of idiopathic acute vestibular dysfunction (vestibular neuritis). Cochrane Database Syst Rev 2011;(5):CD008607.

Gottshall K. Vestibular rehabilitation after mild traumatic brain injury with vestibular pathology. NeuroRehabilitation 2011;29:167-171.

Goudakos JK, Markou KD, Psillas G, Vital V, Tsaligopoulos M. Corticosteroids and vestibular exercises in vestibular neuritis. Single-blind 
randomized clinical trial. JAMA Otolaryngol Head Neck Surg 2014; 140:434-440.

Hall CD, Herdman SJ, Whitney SL, Cass SP, Clendaniel RA, Fife TD, Furman JM, Getchius TS, Goebel JA, Shepard NT, Woodhouse SN. Vestibular rehabilitation for peripheral vestibular hypofunction: an evidence-based clinical practice guideline: from the American Physical Therapy Association Neurology Section. J Neurol Phys Ther 2016;40: 124-155

Igarashi M, Levy JK, O-Uchi T, Reschke MF. Further study of physical exercise and locomotor balance compensation after unilateral labyrinthectomy in squirrel monkeys. Acta Otolaryngol 1981;92:101-105.

Kim JI. Diagnosis and treatment of chronic dizziness. J Korean Bal Soc 2007;6:93-99.

Kim SH. Education in vestibular rehabilitation therapy: 2011 Ad hoc committee on vestibular rehabilitation therapy's guideline. Res Vestib Sci 2013;12:S53-54.

Koo JW, Chang MY, Woo SY, Kim S, Cho YS. Prevalence of vestibular dysfunction and associated factors in South Korea. BMJ Open 2015;5: e008224.

Korea Proprioceptive Neuromuscular Facilitation Association. Education program [Internet]. Korea Proprioceptive Neuromuscular Facilitation Association; 2020 [cited 2020 Feb 21]. Available from: http://www.pnf. or.kr/sub/sub6_2.php.

Korean Academy of Orthopedic Manual Physical Therapy. Education program [Internet]. Korean Academy of Orthopedic Manual Physical Therapy; 2020 [cited 2020 Feb 21]. Available from: http://kaompt.or.kr/ edu/?page_num=0102.

Korean Bobath Association [Internet]. Seongnam (Korea): Korean Bobath Association; 2020 [cited 2020 Feb 21]. Available from: http://www. kbobath.com/.

Korean Physical Therapy Association [Internet]. Seoul (Korea): Korean Physical Therapy Association; 2020 [cited 2020 Feb 21]. Available from: http://www.kpta.co.kr/center/intro/societyInfo.

Lacour M, Manzoni D, Pompeiano O, Xerri C. Central compensation of vestibular deficits. III. Response characteristics of lateral vestibular neurons to roll tilt after contralateral labyrinth deafferentation. J Neu- rophysiol 1985;54:988-1005.

Lee DJ, Rhee CK, Suh MW. Rehabilitation of vestibular hypofunction. Res Vestib Sci 2011;10:S32-37.

Lee HJ, Choi-Kwon S. Effectiveness of self-efficacy promoting vestibular rehabilitation program for patients with vestibular hypofunction. J Korean Acad Nurs 2016;46:710-719.

McDonnell MN, Hillier SL. Vestibular rehabilitation for unilateral peripheral vestibular dysfunction. Cochrane Database Syst Rev 2015;1: CD005397.

National Evidence-based Healthcare Collaborating Agency. HTA-2017-15 [Internet]. Seoul (Korea): National Evidence-based Healthcare Collaborating Agency; 2020 [cited 2020 Feb 21]. Available from: https://nhta. neca.re.kr/nhta/publication/nhtaU0601L.ecg.

Norré ME, Beckers AM. Vestibular habituation training. Specificity of adequate exercise. Arch Otolaryngol Head Neck Surg 1988;114:883-886.

Rhee CK, Jung JY, Chung YW. Practice of vestibular rehabilitation. J Korean Bal Soc 2006;5:149-157.

Sessoms PH, Gottshall KR, Collins JD, Markham AE, Service KA, Reini SA. Improvements in gait speed and weight shift of persons with traumatic brain injury and vestibular dysfunction using a virtual reality computer-assisted rehabilitation environment. Mil Med 2015;180(3 Suppl):143-149.

Shim JH, Kim YS, Yoon TH. Relationships between empowerment, job satisfaction, and organizational commitment among physical therapists. Phys Ther Korea 2008;15:70-79.

Shin JY, Cho BH. The types of the professionalism for the physical therapists in Korea: approach in Q-methodology. Health Soc Sci 2019;51: 41-80.

van Vugt VA, Diaz Nerio PM, van der Wouden JC, van der Horst HE, Maarsingh OR. Use of canalith repositioning manoeuvres and vestibular rehabilitation: a GP survey. Scand J Prim Health Care 2017;35: 19-26.

von Brevern M, Neuhauser H. Epidemiological evidence for a link between vertigo and migraine. J Vestib Res 2011;21:299-304.

Whitney SL, Alghwiri AA, Alghadir A. An overview of vestibular rehabilitation. Handb Clin Neurol 2016;137:187-205. 